\title{
AMILOIDOSE PULMONAR: ASPECTOS NA TOMOGRAFIA COMPUTADORIZADA*
}

\author{
Edson Marchiori ${ }^{1}$, Arthur Soares Souza Jr. ${ }^{2}$, Angela Ferreira ${ }^{3}$, Karla Confessor Azevedo ${ }^{4}$, \\ Suzane Mansur Fialho ${ }^{5}$, Sheila Jandira Vianna Crespo ${ }^{6}$
}

Resumo Neste trabalho foram estudados os aspectos tomográficos observados em cinco pacientes com diagnóstico de amiloidose pulmonar confirmado histopatologicamente. Dois deles apresentaram a forma traqueobrônquica da doença e mostraram nodulações e formação de placas nas paredes traqueais, com calcificações. Dois tinham a forma parenquimatosa difusa, um deles com opacidades reticulares e nodulares subpleurais, e o outro com espessamento nodular de septos interlobulares e consolidações parenquimatosas. Ambos apresentavam calcificações de permeio às lesões. 0 último paciente tinha a forma nodular da doença, com nódulos de contornos regulares em ambos os pulmões, com calcificações. Os aspectos tomográficos observados, embora não patognomônicos, são muito sugestivos do diagnóstico de amiloidose.

Unitermos: Amiloidose; Tomografia computadorizada; Pulmões; Calcificações pulmonares.

Abstract Pulmonary amyloidosis: computed tomography findings.

We report the computed tomography findings of five patients with pathology proven pulmonary amyloidosis. Tracheobronchial amyloidosis with calcified nodules and plaques in the tracheal wall were seen in two patients. Two other patients had diffuse parenchymal disease with calcified lesions, one had reticular and nodular subpleural opacities whereas the other had nodular interlobular septal thickening and a parenchymal consolidation. The latter presented the nodular type of the disease with multiple sharp nodules scattered throughout the lungs and interspersed calcifications. The computed tomography findings observed were not specific but strongly suggestive of amyloidosis.

Key words: Amyloidosis; Computed tomography; Lungs; Pulmonary calcifications.

\section{INTRODUÇÃO}

Amiloidose é uma doença de origem indeterminada, caracterizada pela deposição extracelular anormal de material amilóide ${ }^{(1-4)}$.

As numerosas classificações propostas, baseadas na localização, nos aspectos clínicos e nas características químicas do amilóide, mostram a limitada compreensão da doença, mesmo nos dias atuais. De

\footnotetext{
* Trabalho realizado no Departamento de Radiologia da Universidade Federal Fluminense (UFF), Niterói, RJ, e no Serviço de Radiodiagnóstico do Hospital Universitário Clementino Fraga FiIho (HUCFF) da Universidade Federal do Rio de Janeiro (UFRJ), Rio de Janeiro, RJ.

1. Professor Titular de Radiologia da UFF, Coordenador Adjunto do Curso de Pós-Graduação em Radiologia da UFRJ.

2. Professor Adjunto de Radiologia da Faculdade de Medicina de São José do Rio Preto (Famerp), SP.

3. Professora Adjunta de Pneumologia da UFF.

4. Médica Pós-graduanda do Serviço de Radiologia da Santa Casa de Misericórdia do Rio de Janeiro, RJ.

5. Médica da Clínica Radiológica Emílio Amorim, Rio de Janeiro, RJ.

6. Professora Adjunta de Radiologia da UFF, Médica do Instituto Nacional do Câncer (INCA), Rio de Janeiro, RJ.

Endereço para correspondência: Prof. Dr. Edson Marchiori. Rua Thomaz Cameron, 438, Valparaíso. Petrópolis, RJ, 25685-120. E-mail: edmarchiori@zipmail.com.br

Recebido para publicação em 16/9/2002. Aceito, após revisão, em 31/10/2002.
}

maneira simplificada, a doença pode ser subdividida em forma localizada (quando o material é depositado em um único órgão) e forma sistêmica (quando afeta mais de um órgão). Ela pode também ser classificada como primária (aquela sem uma causa predisponente ou coexistente) ou secundária (quando existe uma doença causal associada) $^{(4-7)}$.

A forma sistêmica secundária está, em geral, relacionada a processos neoplásicos, infecciosos ou inflamatórios crônicos, incluindo tuberculose, doença renal crônica (particularmente pielonefrite), sífilis, lepra, doença inflamatória intestinal, osteomielite, infecções parasitárias, artrite reumatóide, bronquiectasias, e outros ${ }^{(3,6,7)}$. A incidência de comprometimento pulmonar com significado clínico ou radiológico na forma secundária é muito baixa ${ }^{(3,7,8)}$.

A grande maioria dos pacientes com comprometimento pulmonar apresenta a forma primária da doença ${ }^{(3,6,8)}$. Amiloidose pulmonar primária é uma doença rara, que ocorre com características localizadas (formas traqueobrônquica e nodular pulmonar) ou com características sistêmicas (forma parenquimatosa difusa ou septal alveolar) ${ }^{(9)}$.

$\mathrm{Na}$ forma sistêmica primária, fibrilas amilóides podem ocorrer em outros órgãos, como coração, rins, língua, trato gastrointestinal, paredes de vasos sanguíneos, nervos, pele, músculos, estruturas periarticulares e outros sítios ${ }^{(\mathbf{1})}$. Cerca de $10 \%$ a $15 \%$ dos pacientes com esta forma da doença têm mieloma múltiplo associado ${ }^{(\mathbf{3})}$.

Neste estudo são apresentados os aspectos tomográficos observados em cinco casos de amiloidose com comprometimento do aparelho respiratório.

\section{CASUÍSTICA E MÉTODOS}

Foram estudados cinco casos de amiloidose pulmonar, observados em três diferentes instituições hospitalares do Rio de Janeiro e de São Paulo, todos com comprovação anatomopatológica. A idade dos pacientes variou de 45 a 76 anos, com média de 57 anos.

Não houve padronização nas rotinas dos exames, uma vez que foram realizados em aparelhos de diferentes instituições. 


\section{RESULTADOS}

Dois pacientes apresentavam a forma traqueobrônquica da doença, dois tinham a forma parenquimatosa difusa, e um, a forma nodular.

As duas pacientes com a forma traqueobrônquica eram do sexo feminino, uma delas com 57 anos de idade e a outra com 58 anos. Clinicamente, queixavam-se de tosse seca, falta de ar e dispnéia aos esforços. Uma delas relatava também rouquidão. Ambas apresentavam múltiplas nodulações e espessamento em placas das paredes traqueais, com calcificações em alguns locais (Figura 1). Tinham também lesões semelhantes nos brônquios principais.
Os dois pacientes com a forma parenquimatosa difusa cursavam com dispnéia, há três e quatro meses, respectivamente. Um era do sexo masculino, com 76 anos de idade, e o outro, do sexo feminino, com 50 anos. O paciente do sexo masculino mostrava opacidades lineares e nodulares nas bases pulmonares, predominando nas regiões subpleurais, com calcificações de permeio (Figura 2). A outra paciente apresentava espessamento difuso de septos interlobulares, com nodulações ao longo de alguns septos e também da cissura oblíqua à esquerda. Evidenciavam-se também consolidações nos lobos inferiores, com calcificações puntiformes de permeio, além de derrame pleural bilateral (Figura 3).
A paciente com a forma nodular, uma mulher de 45 anos de idade, queixava-se de tosse seca há quatro anos. O exame tomográfico mostrou múltiplos nódulos e massas, de tamanhos variados, contornos irregulares, a maior parte com calcificações amorfas de permeio. Um deles apresentava também área de escavação (Figura 4).

Todos os pacientes foram submetidos a biópsias, que em comum mostraram deposição de tecido amilóide na traquéia ou nos pulmões (Figura 5).

\section{DISCUSSÃO}

Num extenso levantamento de necropsias feito por Smith et al. ${ }^{(7)}$, abrangendo um

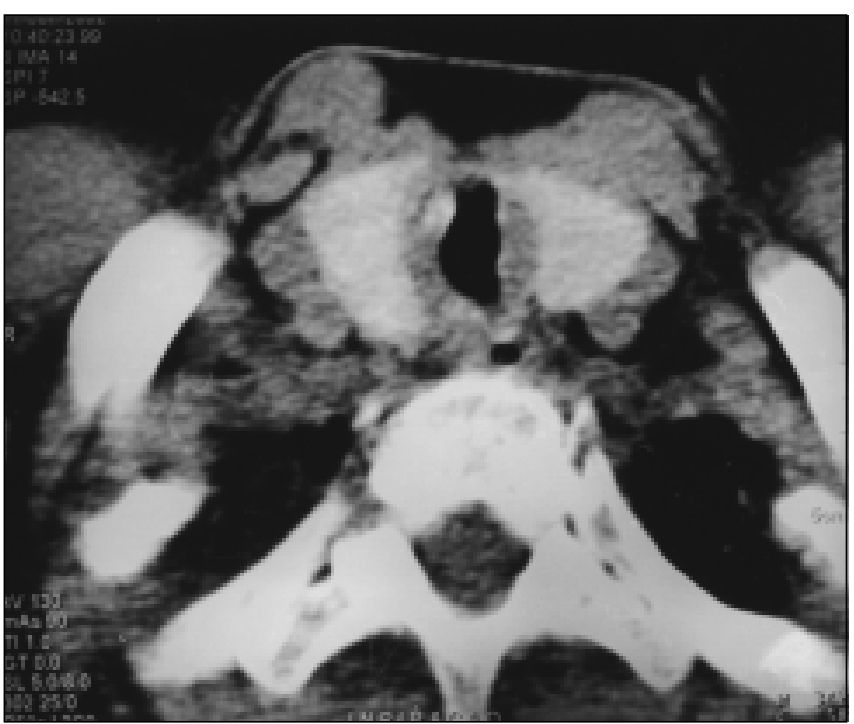

A

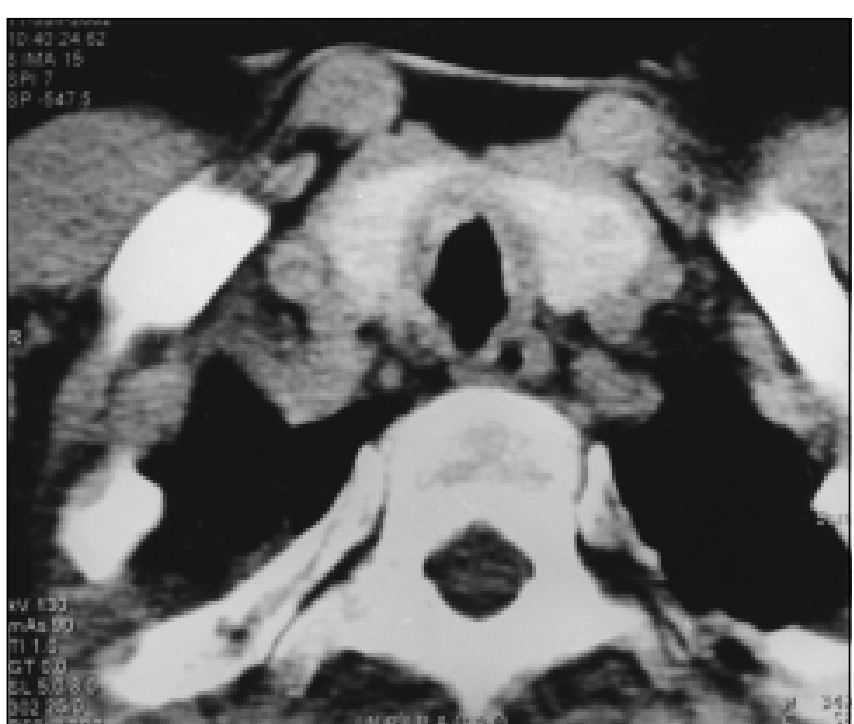

B
Figura 1. Tomografia computadorizada mostrando traquéia com luz irregular, determinada pela presença de múltiplas lesões nodulares, com formação de placas nas suas paredes. Observam-se também discretas calcificações em algumas das nodulações.

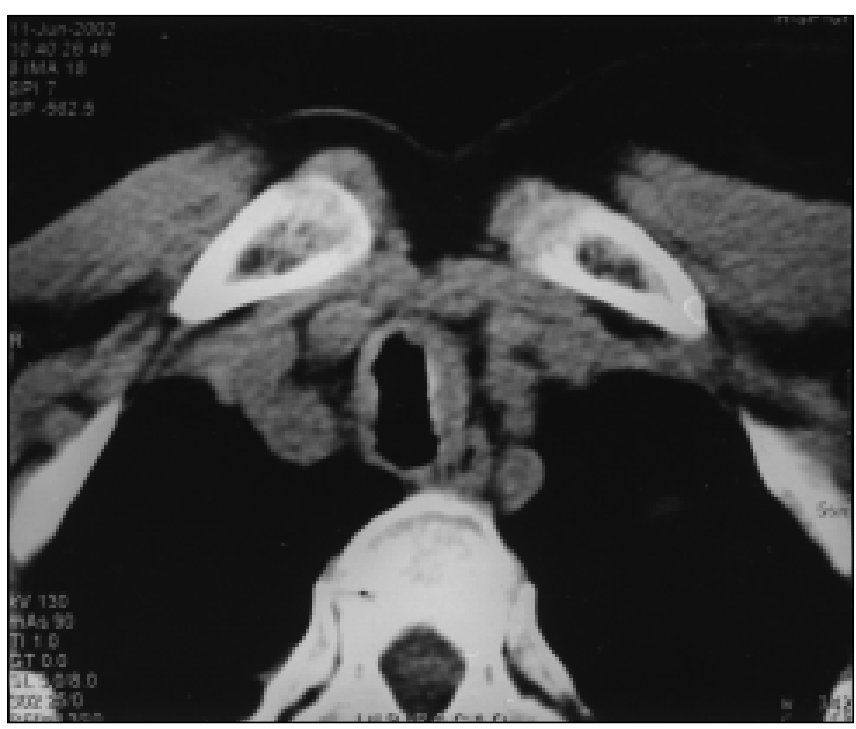

C 


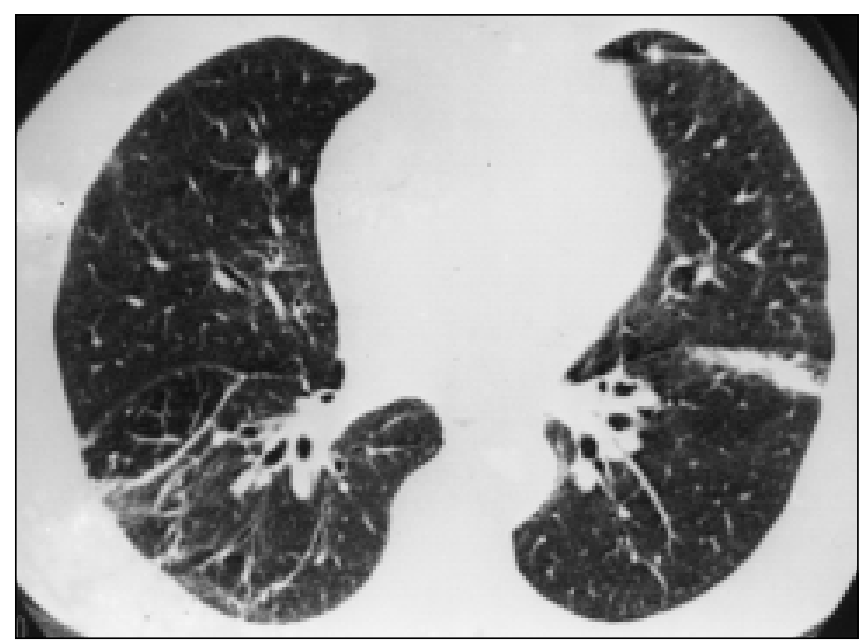

A

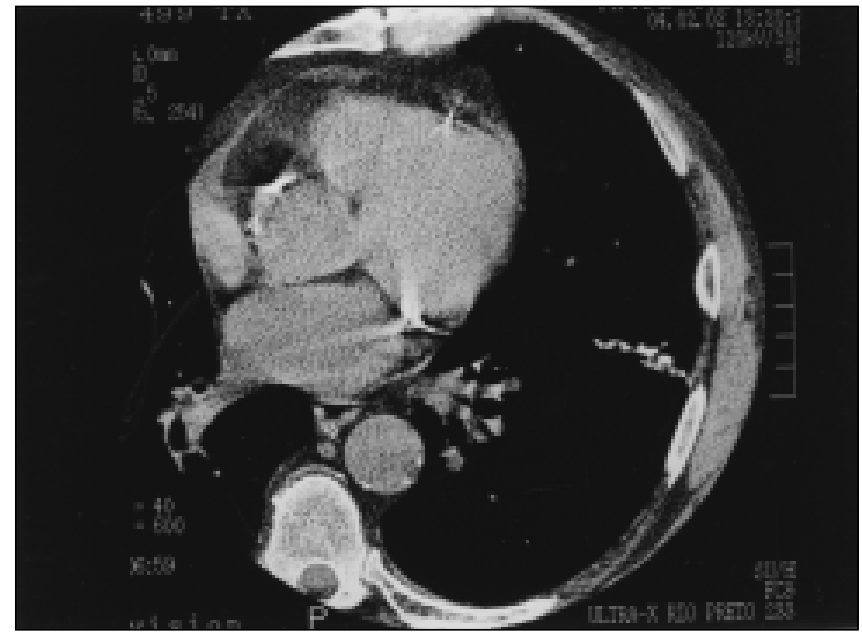

C

Figura 2. Tomografia computadorizada de alta resolução, com janelas para parênquima pulmonar e mediastino, mostrando discretas opacidades nodulares e reticulares nas bases pulmonares, predominando nas regiões subpleurais. Evidencia-se também opacidade em faixa junto à cissura oblíqua à direita. Nas janelas para mediastino observam-se calcificações em correspondência com as lesões.

período de cerca de 90 anos, 223 pacientes com amiloidose foram estudados. Destes, havia comprometimento pulmonar em $68(31 \%)$, sendo 31 com a chamada forma senil da doença, 23 com a forma primária, oito associados a mieloma múltiplo, dois com uma forma classificada como familiar, três com a forma nodular isolada, e apenas um com a forma secundária. Deposição amilóide senil é um achado ocasional em alguns pacientes em necropsias. É estimado ocorrer em $10 \%$ dos pacientes com mais de 80 anos de idade e em $50 \%$ daqueles com mais de $90 \operatorname{anos}^{(\mathbf{3})}$.

A quase totalidade dos pacientes com amiloidose pulmonar tem amiloidose cardíaca associada, por vezes com quadro clínico mais grave que o pulmonar ${ }^{(7)}$.
Em relação à distribuição das lesões no aparelho respiratório, a amiloidose pode ser dividida, didaticamente, nas seguintes formas: traqueobrônquica, nodular pulmonar, e septal alveolar ou parenquimatosa difusa $^{(\mathbf{1}, 4,5,9)}$.

A forma traqueobrônquica é o tipo mais comum da doença ${ }^{(\mathbf{1})}$. A tomografia computadorizada pode mostrar nódulos, únicos ou múltiplos, fazendo protrusão na parede da traquéia e/ou brônquios ou, mais comumente, espessamento difuso, circunferencial, das paredes brônquicas, com placas submucosas multifocais ${ }^{(\mathbf{1 , 3})}$. A parede espessada pode apresentar calcificações ${ }^{(4,5)}$. Alterações parenquimatosas secundárias à obstrução brônquica podem ser vistas, do tipo colapso, consolidações infecciosas recorrentes, bronquiectasias e hiperinsuflação obstrutiva ${ }^{(\mathbf{1 , 4})}$.

O diagnóstico diferencial da forma traqueobrônquica deve ser feito com tuberculose traqueobrônquica, traqueobroncopatia osteoplástica e policondrite relapsan$\mathrm{te}^{(4)}$. Esta forma da doença tem sido associada com a traqueobroncopatia osteoplástica, que se caracteriza pela presença de nódulos submucosos calcificados ou ossificados na árvore traqueobrônquica. Alguns autores sugerem que a amiloidose traqueobrônquica leva à traqueobroncopatia osteoplástica, enquanto outros não concordam com esta relação ${ }^{(3)}$.

A forma nodular é mais comum em pacientes com mais de 60 anos de idade, em geral assintomáticos, e se caracteriza 


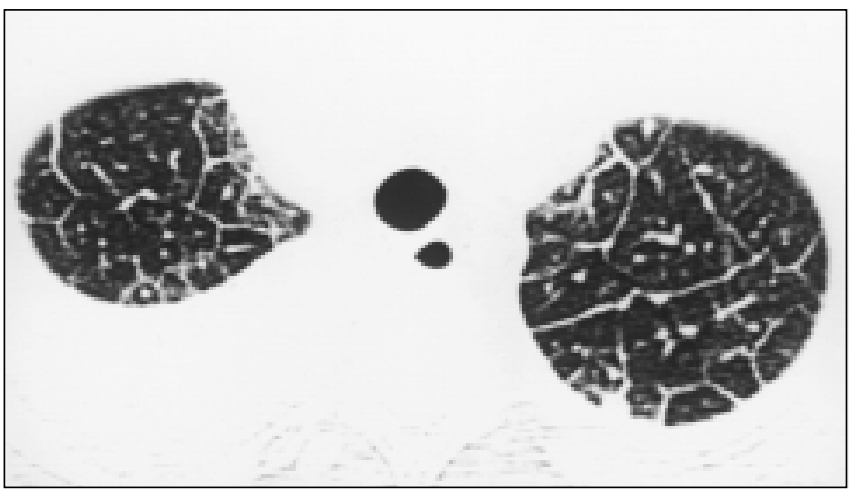

A
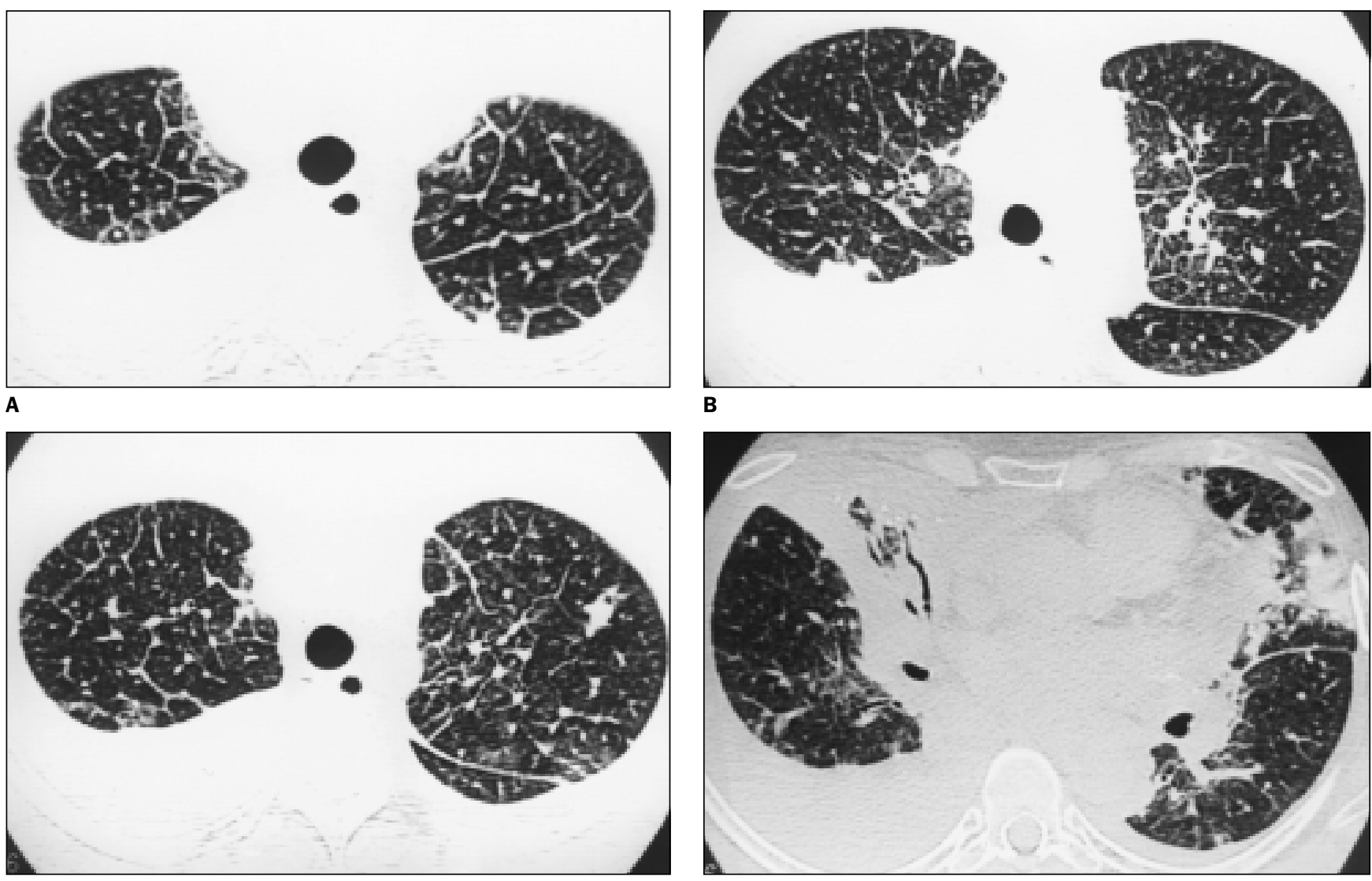

B

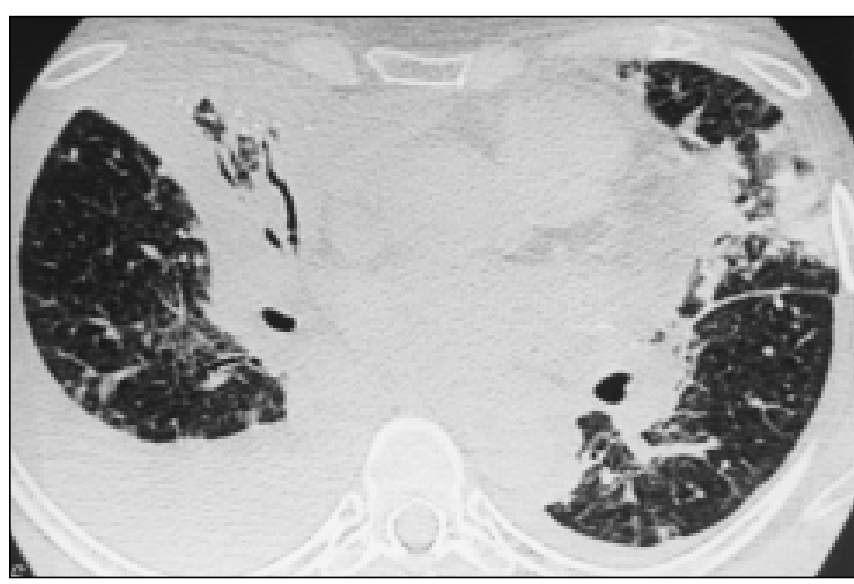

C

\section{D}

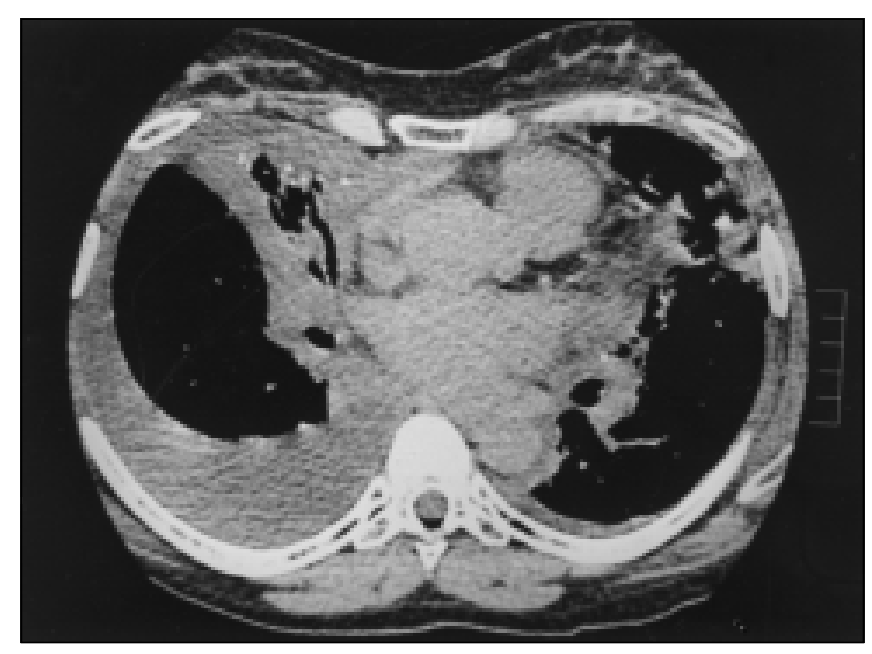

E

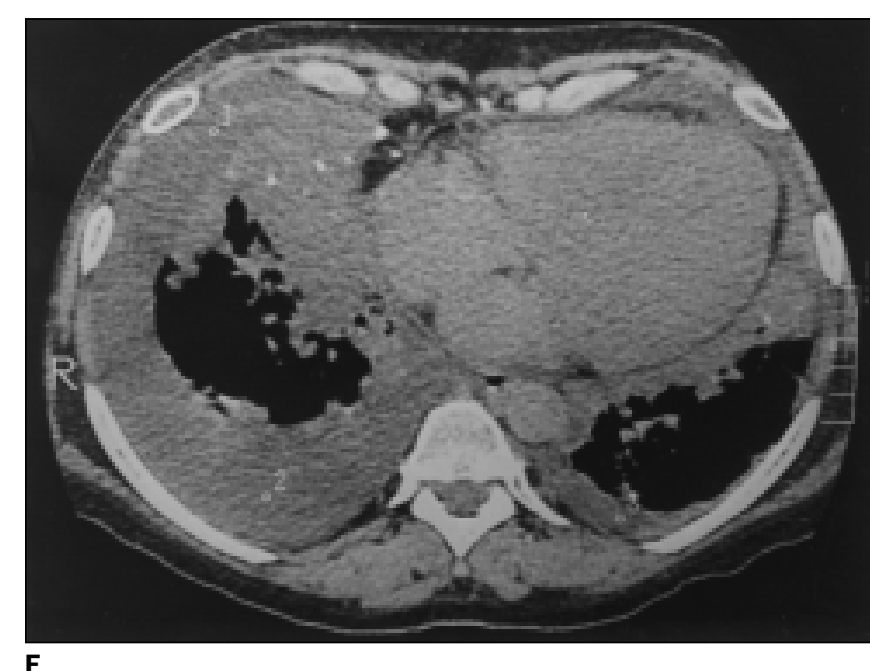

Figura 3. Em A, B e C, cortes dos campos superiores, observa-se espessamento difuso de septos interlobulares, com nodularidade. Notam-se também nodulações em correspondência com a cissura oblíqua à esquerda. Em $\mathbf{D}, \mathbf{E}$ e $\mathbf{F}$, cortes das bases pulmonares, evidenciam-se consolidações nos lobos inferiores, com broncograma aéreo e pequenos focos de calcificação puntiformes de permeio, predominando à direita. Nota-se derrame pleural bilatera $\mathrm{I}$, mais extenso à direita.

pela presença de nódulos solitários ou múltiplos no parênquima pulmonar. Os nódulos não são uniformes no tamanho, número ou forma, e são freqüentemente bem definidos. Em cerca da metade dos casos focos de calcificação ou ossificação podem ocorrer ${ }^{(\mathbf{1 , 3 , 4 , 1 0})}$. Os nódulos crescem lentamente, por anos, e não involuem. $\mathrm{O}$ tamanho varia de micronódulos até massas de cerca de 15 centímetros ${ }^{(4)}$. De regra, escavação nos nódulos é muito rara ${ }^{(2)}$, embora possa ocorrer ${ }^{(\mathbf{1 0})}$.

O diagnóstico diferencial da forma nodular é feito principalmente com neopla- sias primárias ou metastáticas, e com doenças granulomatosas ${ }^{(4)}$, particularmente com os granulomas hialinizantes ${ }^{(\mathbf{1 0})}$.

A forma parenquimatosa difusa, em geral, aparece após a sexta década de vida, havendo envolvimento quase exclusivamente intersticial, com infiltração amilóide 


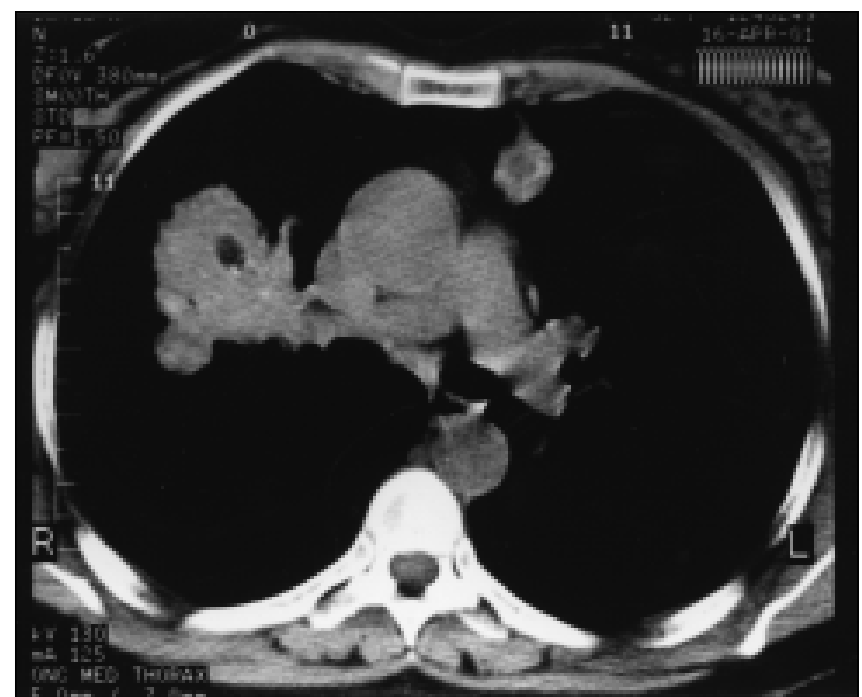

A

Figura 4. Tomografia computadorizada mostrando múltiplas lesões nodulares de contornos irregulares em ambos os pulmões, apresentando calcificações amorfas de permeio. Em A, uma das lesões está escavada. Nota-se também, em C, à esquerda, uma lesão com formato triangular, com a base voltada para a superfície pleural.

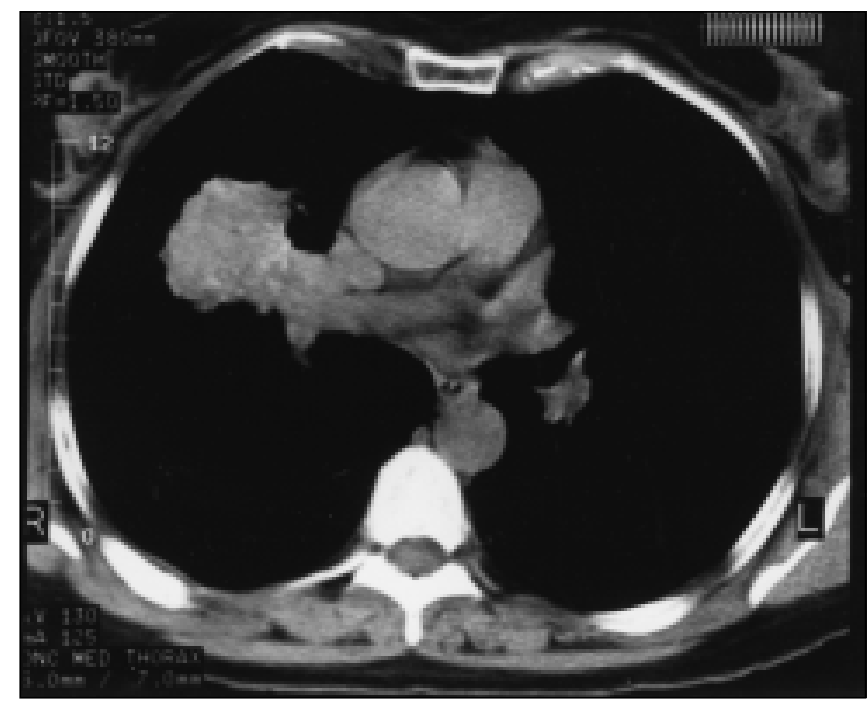

B

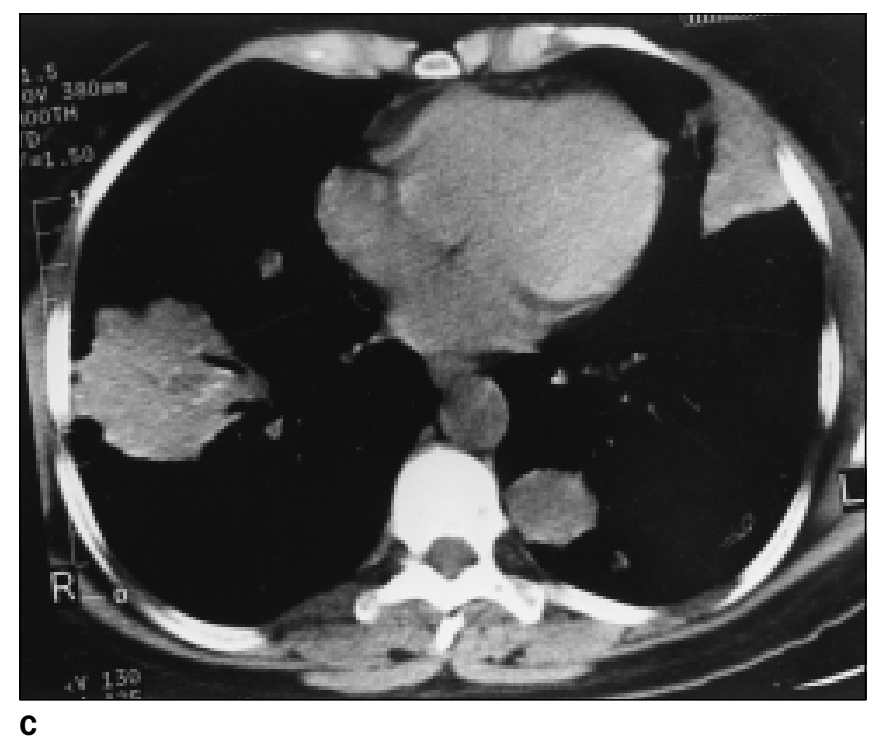

C

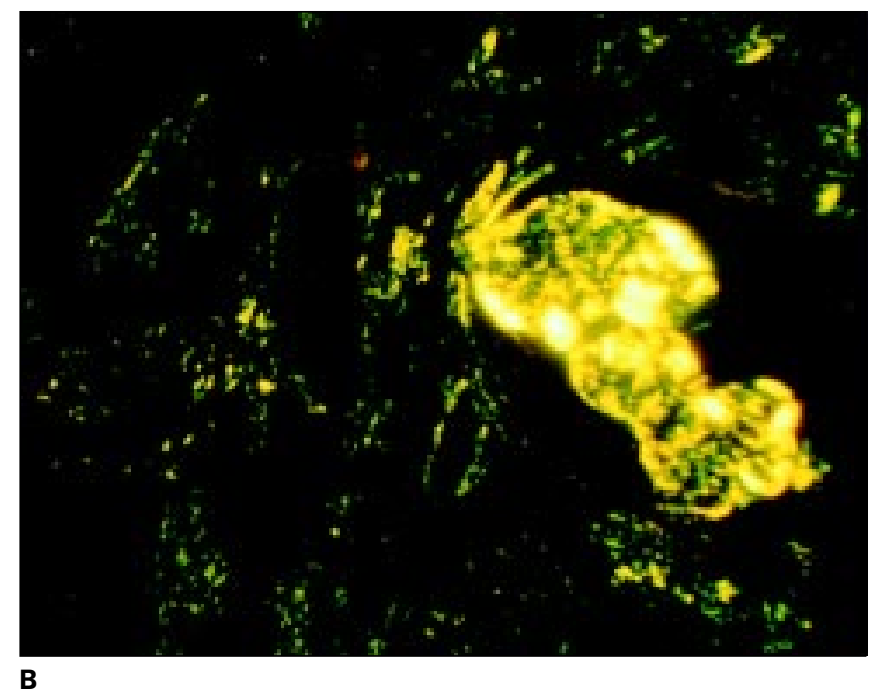

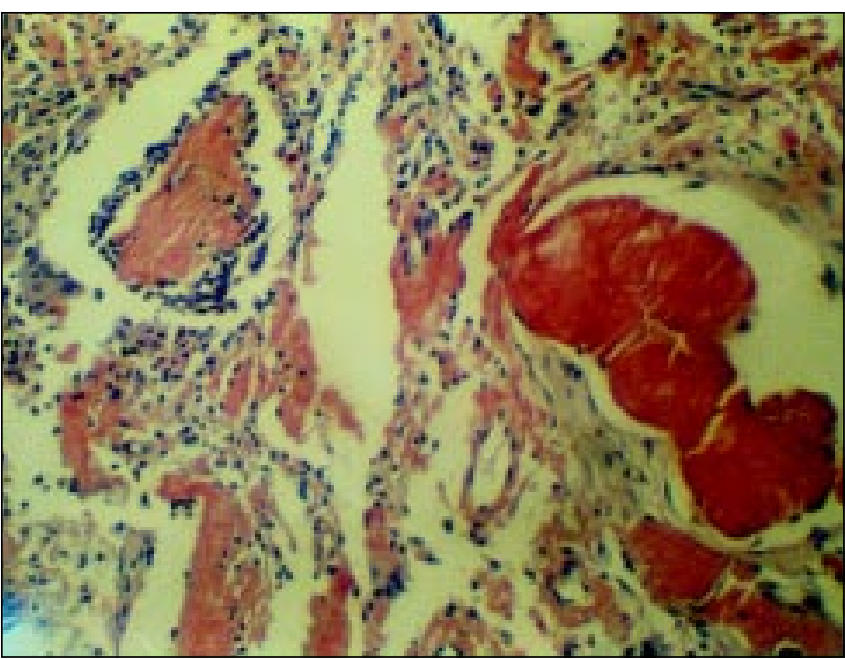
à luz polarizada, mostrando birrefringência esverdeada do material amilóide. 
difusa dos septos alveolares, particularmente do interstício ao redor dos capilares $^{(\mathbf{1})}$. Radiologicamente, manifesta-se como opacidades intersticiais ou alveolares, não específicas, que se alteram muito pouco com o tempo ${ }^{(\mathbf{9})}$. Na tomografia computadorizada de alta resolução são observadas opacidades reticulares anormais, com espessamento de septos interlobulares, pequenos nódulos, bem definidos, de 2 a 4 milímetros de diâmetro, e opacidades confluentes, predominando nas regiões subpleurais. Calcificações puntiformes nos nódulos ou nas consolidações podem

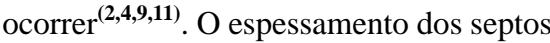
interlobulares pode ser nodular ou irregular. O mesmo aspecto é observado nas bainhas peribroncovasculares e nas cissuras ${ }^{(\mathbf{1})}$. Menos freqüentemente, a amiloidose sistêmica se apresenta com padrão de pequenos nódulos, simulando sarcoidose ou tuberculose miliar ${ }^{(\mathbf{1 1})}$. Linfonodomegalias mediastinais e/ou hilares podem estar presentes ${ }^{(\mathbf{1}, \mathbf{2})}$, às vezes se apresentando com calcificações $^{(\mathbf{2 , 3 , 1 2})}$. Outros achados são cardiomegalia $^{(\mathbf{1 2})}$ e sinais de fibrose, como faveolamento e bronquiectasias de tração ${ }^{\mathbf{( 2 , 1 2 )}}$. Comprometimento pleural ocorre raramente, podendo se expressar como derrame pleural ${ }^{(\mathbf{2 , 1 0 , 1 2})}$.

Clinicamente, a amiloidose não tem preferência por sexo e atinge ampla faixa etária, com casos descritos da quarta à décima década de vida. A amiloidose parenquimatosa difusa é a forma menos comum da doença e a mais grave. $\mathrm{O}$ sintoma de apresentação mais comum é a dispnéia progressiva $^{(9)}$. O prognóstico é muito pior que o das outras formas ${ }^{(\mathbf{6})}$, e a sobrevida média após o diagnóstico é de cerca de um ano e meio ${ }^{(3)}$. A forma traqueobrônquica causa em geral sibilância crônica, dispnéia e tosse (achados que levam à confusão com asma), hemoptise e infecções respiratórias de repetição ${ }^{(\mathbf{4})}$. Apesar da sua natureza localizada e de poder ser assintomática, ocasionalmente resulta em morbidade significativa devida aos fenômenos obstrutivos ${ }^{(3)}$. Amiloidomas localizados se caracterizam por um curso benigno ${ }^{(3)}$.

O diagnóstico histopatológico é feito pelo encontro de amilóide, que é um material inerte, protéico, homogêneo, acelular e eosinofílico, que histoquimicamente se cora pelo vermelho Congo e mostra birrefringência verde à luz polarizada ${ }^{(2-6,10,12)}$. $\mathrm{Na}$ forma traqueobrônquica depósitos da substância amorfa na submucosa formam nódulos irregulares ou lâminas difusas. $\mathrm{O}$ epitélio brônquico que os recobre, em geral se mantém intacto. Infiltrado linfoplasmocitário e células gigantes podem ser vistos na periferia dos depósitos. Dentro das coleções de amilóide, pequenos ninhos de cartilagem podem ser observados, além de focos de calcificação e metaplasia óssea. $\mathrm{Na}$ forma nodular, massas de amilóide envolvidas por células plasmáticas, linfócitos e células gigantes são os achados mais comuns. Essas massas podem sofrer calcificação, com ou sem ossificação. Na forma alveolar septal o amilóide se deposita entre a luz capilar e as células de revestimento alveolar. Depósitos vasculares de ami- lóide, geralmente localizados na muscular ou na média de artérias e arteríolas pulmonares, podem acompanhar qualquer dos padrões de doença parenquimatosa ${ }^{(6,7,10)}$.

\section{REFERÊNCIAS}

1. Geusens EA, Verschakelen JA, Bogaert JG. Primary pulmonary amyloidosis as a cause of interlobular septal thickening. AJR 1997;168:116-7.

2. Pickford HA, Swensen SJ, Utz JP. Thoracic crosssectional imaging of amyloidosis. AJR 1997;168: 351-5.

3. Utz JP, Swensen SJ, Gertz MA. Pulmonary amyloidosis. The Mayo Clinic experience from 1980 to 1993. Ann Intern Med 1996;124:407-13.

4. Kim HY, Im JG, Song KS, et al. Localized amyloidosis of the respiratory system: CT features. J Comput Assist Tomogr 1999;23:627-31.

5. Gutiérrez MN, Torrealba BJ, Mendoza JN, Náquira NN. Amiloidosis sistémica primaria con compromiso pulmonar difuso: causa infrecuente de enfermedad intersticial. Caso clínico. Rev Méd Chile 1997;125:1187-91.

6. Scully RE, Mark EJ, McNeely WF, Ebeling SH. Case records of the Massachusetts General Hospital. N Eng J Med 1996;335:266-73.

7. Smith RRL, Hutchins GM, Moore GW, Humphrey RL. Type and distribution of pulmonary parenchymal and vascular amyloid. Correlation with cardiac amyloidosis. Am J Med 1979;66:96-104.

8. González-Cueto DM, Rigoli M, Gioseffi LM, Lancelle B, Martínez A. Diffuse pulmonary amyloidosis. Am J Med 1970;48:668-70.

9. Graham CM, Stern EJ, Finkbeiner WE, Webb WR. High-resolution CT appearance of diffuse alveolar septal amyloidosis. AJR 1992;158:265-7.

10. Katzenstein ALA. Katzenstein and Askin's Surgical pathology of non-neoplastic lung disease. 3rd ed. Philadelphia: Saunders, 1997.

11. Webb WR, Muller NL, Naidich DP. High-resolution CT of the lung. 3rd ed. Philadelphia: Lippincott Williams \& Wilkins, 2001.

12. Wilson SR, Sanders DE, Delarue NC. Intrathoracic manifestations of amyloid disease. Radiology 1976; 120:283-9. 